\title{
On Studying the Mis-Translation of the Poems of Yu Xuanji through the Comparison of Original Texts and Translation Version
}

\author{
Jinling* \\ Graduate student of Hunan University, China
}

*Corresponding Author: Jinling, Graduate student of Hunan University, China

\begin{abstract}
This essay focuses on analyzing causes of mistranslation of the poems of Yu Xuanji by David Young through text analysis and comparison of the translation version of David Young and that of Leonardo $N g$.
\end{abstract}

\section{INTRODUCTION}

$\mathrm{Yu}$ Xuanji is one of the prominent female poets of Tang dynasty. She lived most of her life in Chang an, the capital city of Tang dynasty. At the age of sixteen, She married censor Li yi, and three years later she was abandoned. After living in Jiangling for a while, she came to live in a Taoist convent where she became a nun and courtesan. When she was about twenty seven, she was executed for murdering her maid. In her short and sad life, we could know that she had tried at least three of the available roles by which women could achieve the accomplishments that were supposed for men. Firstly, as a concubine in her family, her literary talents were admired and encouraged by her husband Li yi. Secondly, as a Taoist nun, she could lived a soul searching and intellectual life in the community. Finally, as a courtesan, she could associate with well educated and powerful men who could appreciate her literary talents, intellectual wits and personal attractiveness. It was with these different roles that she could obtain different perspectives into life and took more initiative to discover round facets of life. As a result from her life experiment, many good pieces were created. The themes of her poems cover different aspects, but missing her husbands, flirting with other writers and lovers, and pondering about spiritual truths was the staple.

English translation of the Complete Poems of Yu Xuanji so far has three versions. The Clouds Float North is by David Young and Jiann I. Lin published in 1998; the Beheaded Poetess is by the Poet Laureate Jean Elizabeth Ward published in 2008; and another version is the newest one translated by Leonardo $\mathrm{Ng}$ who is proficient both in the language and culture of Chinese and English. This paper will only compare the two versions by Leonardo and David. The translation version of Leonardo $\mathrm{Ng}$ is favorable, because the translation is accurate, fluent and elegant. Leonardo $\mathrm{Ng}$ was born in Singapore in 1979. He studied English literature and Sociology at the National University of Singapore, and he is the author of the poetry collections This Mortal World and Changes and Chances, the former shortlisted for the 2012 Singapore Literature Prize. He is also the translator of several classical Chinese works into English, including the Tao Te Ching, The Art of War, The Complete Poems of Yu Xuanji and Lu Ji's Rhapsody on Literature.

The Clouds Float North; The Complete Poems of Yu Xuanji is by David Young and Jiann I. Lin. Jiann I. Lin is an East Asian librarian of Oberlin University. He provided the entire input of traditional Chinese characters by using a computer program to select characters that would be faithful to the classical texts( David 8). With the help of Jiann I. Lin, David Young was able to proceed this project. In 1936, David Young was born in Davenport, Iowa. He earned a BA from Carleton College, and an $\mathrm{MA}$ and $\mathrm{PhD}$ from Yale University. He is the author of several collections of poetry, including Field of Light and Shadow (Knopf, 2010) and Black Lab (2006). At the White Window (2000); Night Thoughts and Henry Vaughan (1994), which won the Ohio State University Press/The Journal Award in Poetry. Young has also published numerous volumes of translation, including Out on the Autumn River: Selected Poems by Du Mu (2006) and Clouds Float North: The Complete Poems of Yu 
Xuanji (1998), both with Jiann I. Lin; Selected Poems by Eugenio Montale (2004), with Charles Wright and Jonathan Galassi); The Poetry of Petrarch (2004); The Book of Fresh Beginnings: Selected Poems of Rainer Maria Rilke (1994), and others.

The translation of Yu xuanji's poem by David young did help to promote the spreading of Yu's poems in the US, but there were many inaccurate translations inside. There are many reasons for his mistranslation, such as the language barrier, lack of culture background, and direct translation of words and sentences. Such mistranslation, to some extent, has distorted the original meaning of the poem, so as to cause a loss of the authenticity and accuracy of the poem, which is definitely not good for introducing the poet. "That is, there are things in these renditions that no poet writing in Yu's language would have said, regardless of whether they might do or think them. The ubiquitous use of "lover" to render a range of more subtle words is especially jarring. Also, Young d-parallels almost all Yu's couplets and treats dozens of lines too carelessly. This makes it hard to see Yu's textures: how her inventiveness perks up in her couplets to the skilled poet Wen Tingyun, for instance, or how her no-nonsense frankness differentiates her work from other Tang courtesans such as Xue Tao or Li Zhi. Dozens of unintended wrong reading distort whole pieces, affecting at least a third of the collection" (Pease 1129).

\section{BODY}

This part will give some typical examples of the wrong translations of Yu's poems by David Young, analyse the causes of mistranslation and make comparison of the two translation versions respectively by David Young and Leonardo Ng.

\begin{tabular}{|c|c|}
\hline 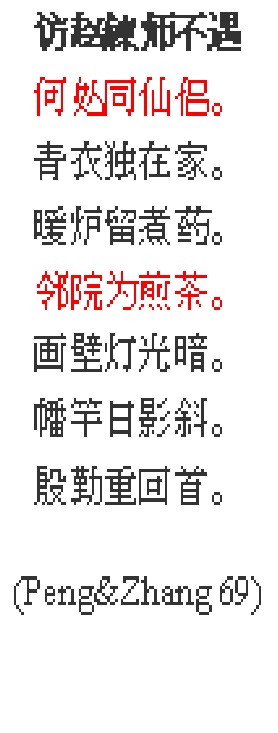 & $\begin{array}{l}\text { Visiting Master Zhao and Not } \\
\text { Finding Him } \\
\text { I wanted to be with someone of } \\
\text { spiritual refinement } \\
\text { I find his house is empty, only the } \\
\text { maid is home his crucible's still } \\
\text { warm from cooking up herb } \\
\text { medicines outside in the courtyard } \\
\text { tea leaves are still simmering a few } \\
\text { dim lamps next to the painted walls } \\
\text { a long shadow by the signal } \\
\text { pole that faces the setting sun as I } \\
\text { leave I heep turning arownd hoping } \\
\text { to find he's come back- just a few } \\
\text { blooming branches brushing the } \\
\text { outside walls. (David } 35 \text { ) }\end{array}$ \\
\hline
\end{tabular}

$1-1$

In this poem, there were some wrong understandings. First, as the title shown that the poem was about Yu paying a visit to Master Zhao and she didn’t find him. In the first Sentence “何处同仙侣”, the original meaning was that $\mathrm{Yu}$ was wondering where the master was going and was he with his soul friend back then? (69) Because the following sentence “青衣独在家” already showed Master Zhao was gone and there was only the maid at home. While the authors translated it into that "I wanted to be with someone of spiritual refinement". Apparently, it was a wrong interpretation. Let's look at the translation by Leonardo:

\subsection{Visiting Master Zhao and Not Finding Him}

Where might you be, with your immortal companions?

Only your servant is home;

You've left herbs cooking on the warm brazier, tea leaves brewing in the next courtyard. The painted walls start to fade in the lamplight, your flagstaff's shadow begins to slant-again and 
On Studying the Mis-Translation of the Poems of Yu Xuanji through the Comparison of Original Texts and Translation Version

again I look around, but beyond the wall, only flowers ( Leonardo, The Complete Poems of Yu Xuanji).

\begin{tabular}{|c|c|}
\hline 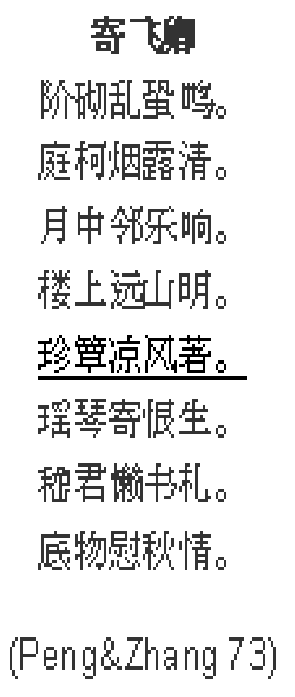 & $\begin{array}{l}\text { Sent to Feicing } \\
\text { Crichets chirp on the stair-steps they } \\
\text { sound confused to me in the misty } \\
\text { courtyard, along the branches, clear } \\
\text { dewdrops hang a moonilit night-I hear } \\
\text { faint music coming from my neighbor's if I } \\
\text { went upstairs I could see the } \\
\text { mountains distinct even in the distance a } \\
\text { cool breeze comes to strohe me as I sit on } \\
\text { my bamboo mat and I wish I had a magic } \\
\text { lute to help me get through this life I feel } \\
\text { like that philosopher who wrote such lazy } \\
\text { letters wanting some way to express the } \\
\text { moods and thoughts of autumn (David 38) }\end{array}$ \\
\hline
\end{tabular}

$2-2$

“珍管凉风著” means the freeze made the bamboo mat cold; and “瑶琴寄恨生” means there was regret and pity inside the lute music, because Yu felt her friendship with the famous poet Wen Tinyun decayed. In the last sentence”嵇君懒书札, 底物慰秋情”, “嵇君”refers to Ji kang, a celebrity from Wei Jin dynasty who was famous for his uprightness and despise for the evil powerful men. Here $\mathrm{Yu}$ compared Wen as Ji kang, which was a compliment. This sentence meant that she rarely received letters from Wen and she couldn't find a way to express her missing. “懒书札” literally meant Wen was lazy and didn't write letters to Yu, while the translation of the authors that "philosophers who wrote such lazy letters wanting some way to express" was apparently a wrong interpretation (75). The reason could be that the authors were lack of Chinese culture knowledge and their Chinese language competency was limited. Let's look at the translation by Leonardo:

\subsection{Sent to Feiqing}

By the stone steps, a confusion of crickets; out in the courtyard, misty dew drenched branches. Music from the house next door echoes in the moonlight; Hills seen from the room above shimmer in the distance.

A cool breeze softly strokes the precious bamboo mat; the jade like qin pours forth sorrow. It seems that you, sir, are too lazy to write letters; lesser things, I guess, will have to soothe these autumn feelings (Leonardo)

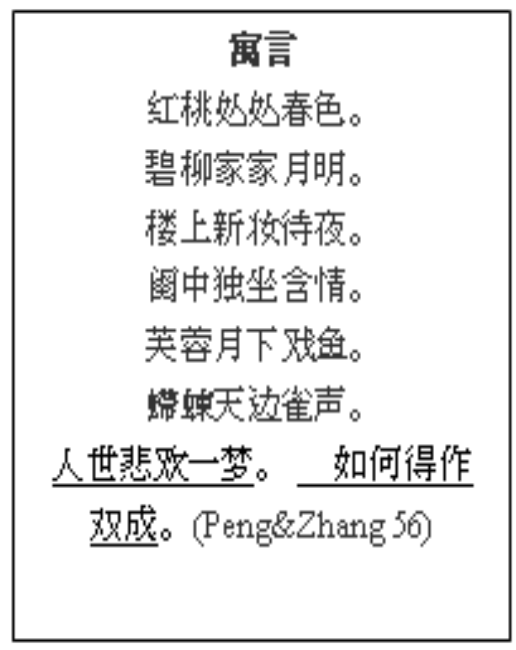

\begin{abstract}
An Allegory
Peach blossoms everywhere, pink color of spring silver willows by every house moon-bright someone upstairs, trying on new clothes waiting for nighffall somebody else, alone in her bedroom drowning in tenderness the carp play around with the lotuses under the moon the sparrows call out to the rainbow at the horizon joys and sorrows, these are the dreams we have in this world why do they always come to us in pairs?(David 45)
\end{abstract}

3-3 
There was a literary quotation in the last sentence “人世悲欢一梦,如何得作双成”. “双成” here didn’t refer to "in pairs", instead it was a name of an ancient fairy who was called Dong Shuangcheng and lived in heaven. In the last sentence, Yu expressed that life was just like a dream, full of happiness and sorrow, and how could she lived happily and freely like the fairy Dong Shuangcheng? (56) While the authors just literally translated that sorrow and joys came in pairs, neglecting the cultural connotation inside. Let's look at the translation by Leonardo:

\subsection{An Allegory}

Red peaches everywhere the color of spring; jade willows by every house gleam in the moonlight. A freshly made-up woman waits upstairs for nightfall; another sits lonely in her room, filled with love. Beneath the moon, fish are playing among the lotuses; from a distant rainbow, the sound of sparrows chirping. Human life-a dream of joy and sorrow mingled; why is it that, gaining one, the other also comes?(Leonardo).

It was a pity that Leonardo also didn't know the literary quotation and literally translated.

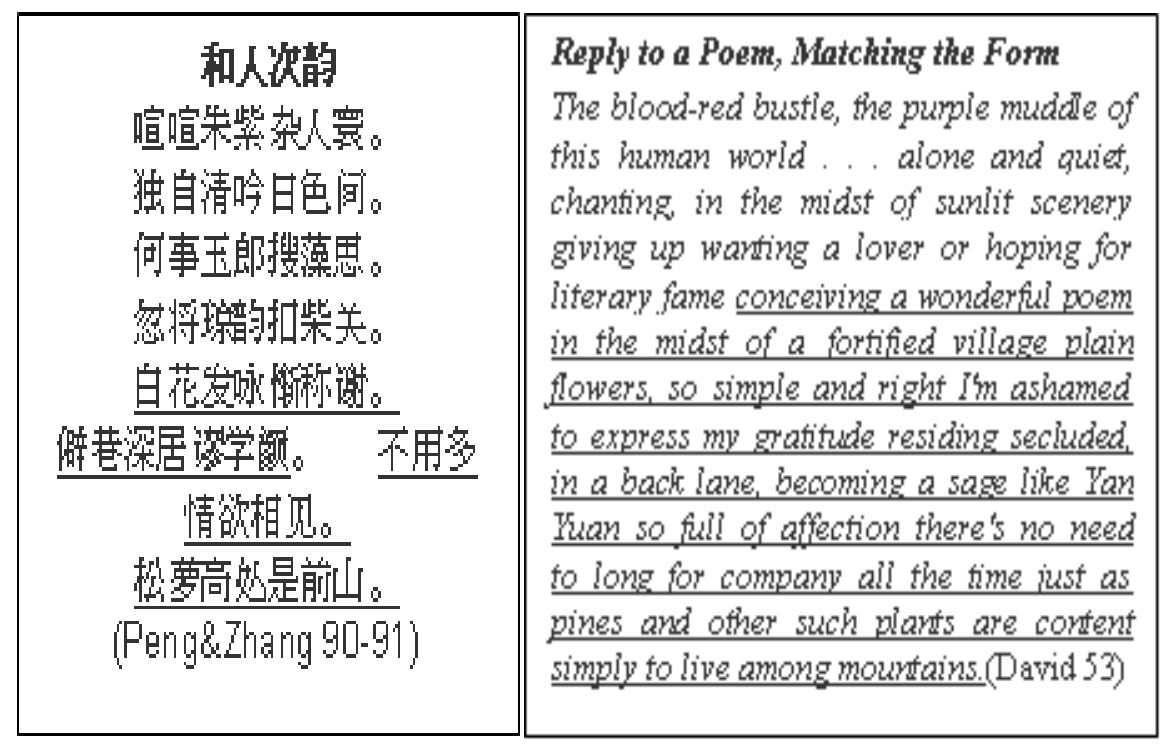

4-4

This poem was dedicated to an admirer of Yu who wrote a letter and brought to her home expressing his affection. From the translation of the authors, we could see their understanding of the poem was totally different from the original meaning. The translation version depicted $\mathrm{Yu}$ as a person who totally immersed herself in the nature and lived a satisfied life without seeking fame and romance. The real meaning of this poem was that if the admirer held affection for her, he didn't have to bother himself specially writing a flattering letter to her. What he only needed to do was coming to meet her at her domicile where Usnea tree grew (90-91). In the sentence“何事玉郎搜藻思,忽将琼韵扣柴关”, “何事”meant “why”, “玉郎” gentleman; Yu was wondering why the gentleman made so many efforts in writing a letter and didn't present it to powerful officials to get promotion, but sent it to her place. “白花发咏惭称谢,僻巷深居谬学颜” was a compliment for Yu from the gentleman. There were two quotations in this sentence. “谢” referred to "Xie Daoyun”, a talented female poet in East Jin dynasty; and “颜”referred to "Yan yuan”, the most diligent and intelligent disciple of Confucius. “白花发咏” was a famous quotation about Xie Daoyun, who creatively compared the snow with flying catkin when she made a poem. The intelligent Yan hui was famous for his diligence on study. Thus the two quotation showed the gentleman's admiration for Yu's intellectual talent, or her talent as a poet. Sometimes, lack of cultural background would made many jokes, such as the translation in this poem. “惭称谢” and “谬学颜” actually meant that Yu felt the gentleman's comparing her to Xie and Yan was too flattering for her. She felt she was not a match with them. However, the author just literally translated it into that "I'm ashamed to express my gratitude"? Because in Chinese “惭” meant ashamed, and “谢” gratitude or thanks. Let's look at the translation by Leonardo: 
On Studying the Mis-Translation of the Poems of Yu Xuanji through the Comparison of Original Texts and Translation Version

\subsection{Harmonizing with Someone Else's Rhyme Words}

Purple and vermilion clash in the noisy world of men; left alone, I sing pure songs in the sunlight. So why have you, good sir, gathered these fine sentiments and come knocking suddenly at my closed brushwood gate? White blossoms make me sing, but I'm no Xie Daoyun; I live deep in a back lane like a fool, like Yen Hui. There's no need for all these words of longing and desire. The place where the pine dwells is first among mountains (Leonardo)

Overall, the translation of Leonardo was compatible with the original meaning, but there were still misunderstandings. First, Yan couldn't be possibly stupid. Second, it didn't mean Yu lived like Yan Hui, but worked hard as Yan did at home.

\begin{tabular}{|c|}
\hline 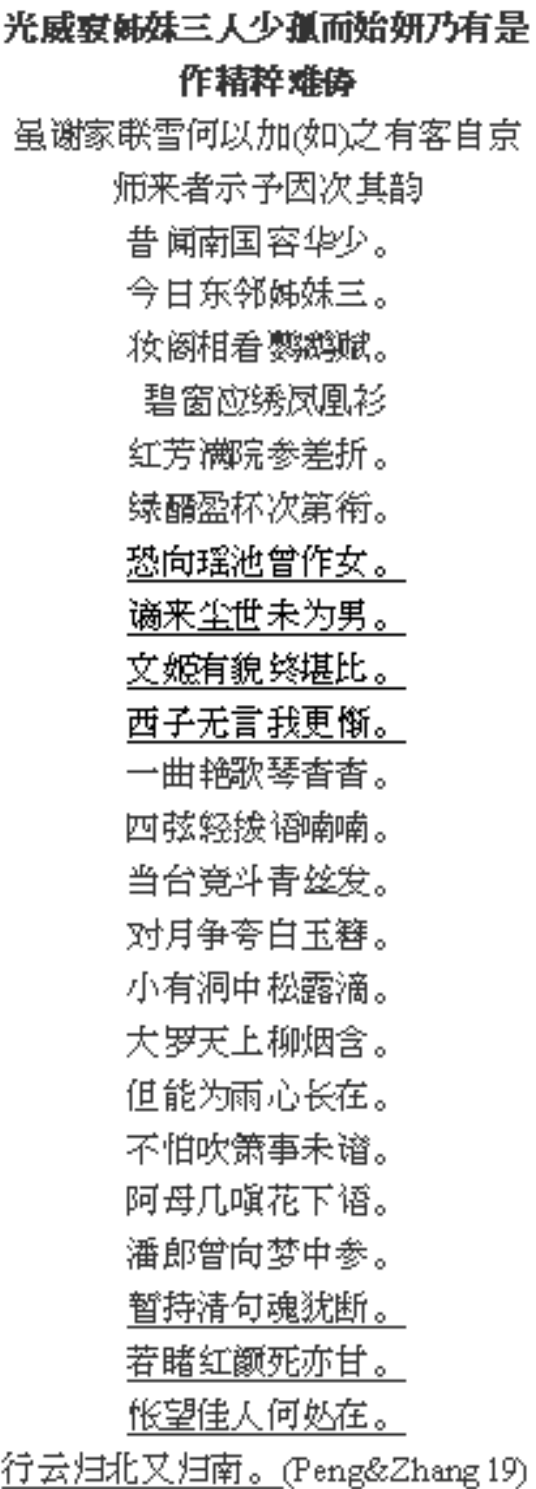 \\
\hline
\end{tabular}

\section{Three Beautiful Sisters, Orphaned Young}

We used to hear about the south, its splendid fresh appearance now it's these eastern neighbors these siters three $u$ in the loft, inspecting their trousseas reciting a verse about parrots sitting by blue-green windows embroidering phoenix garments their courtyard filled with colorful petals like red smoke, billowing unevenly their cups full of good green wine tasted one by one It's dreadful, staring into the mystic pond, hrowing you?l always be female banished from heaven, stuch in this life, unable to do what men do a poet who happens to have some beauty, ends up being compared to a gorgeous woman who's silent- that makes me feel ashamed me, singing solo love songs upon this vanishing zither pluching the four strings softly mur muring the words facing my mirror and dressing table to admire my blach silk hair as if I could rival the moon by flaunting a white jade hairgin $A$ little cave among the pines where dew drips down the shy above the willows a great net filled with mist when you can be like the rain your heart will have strength to go on and you wont be afraid to blow the flute before you ve fully mastered it my mother would get upset because I tallhed to flowers and my lover was from the past a poet who came to me in dreams The spirit makes fine, fresh verses and then is broken it's like watching a lovely young woman give up her will to live these gorgeous young creatures who knows what they?l come to? the clouds float north the clouds float south. (David 54)

$5-5$

This poem was about three beautiful sisters, orphaned young but already showed their talent in their early years, no matter in embroidery, music or writing. There was also misinterpretation in this poem due to their lack of cultural background. In the sentence “文姬有貌终堪比, 西子无言我更惭”, “文姬” referred to Cai Wenji, the daughter of Cai Yi who was a famous man of letters in East Han dynasty. Cai Wenji was beautiful and talented at literature, music and calligraphy. The meaning of the sentence was that the three sisters could be a match to Cai Wenji, and even one of the four Chinese ancient beauties Xi Shi would also have no word about their beauty. I could only feel ashamed for myself in face of their beauty and talent. The translation version of the authors was not accurate enough, omitted lots of information and even distorted the original meaning, shadowing the witty part of Yu's 
poem. The translation of the least but not last sentence was also wrong, because apparently the authors didn't understand correctly. In this sentence “暂持清句魂犹断, 若睹红颜死亦甘, 怅望佳人何处 在”, it meant that those admirers could almost lose their mind just at the sight of the three sister's poems; and they would like to see them face to face even at the price of their lives; but so far they had no idea where the three gorgeous and talented girls were, so they could do nothing but stared at each other (19). Let's look at the translation by Leonardo:

\subsection{Three Beautiful Sisters, Orphaned Young}

I'd long heard that little was lovely in the south, but now I've learnt of these three sisters in the east; together in the dressing-room they read the "Fu on Parrots"; seated by jade windows they embroider phoenix robes. Carefully they pick crimson blossoms in the garden, raising cups of clear green wine one after the other. Perhaps they were once fairy maidens by the Jade Pond, sent in punishment to the dusty world - but not as men! Wenji had beauty, yet endured comparison; Xishi was wordless, yet I feel more ashamed. An alluring melody floats faint from their zithers as they touch the strings lightly, singing softly. Before the mirror they vie against each other's silken tresses, wear jade-white hairpins in competition with the moon. In the Fairy Cave, dew drips from pine trees; in the Highest Heaven, mist envelops willows. But as long as one has a mind for love there's no need to fear ignorance of the flute story Mama's scolded them for exchanging words among the flowers with handsome men who've met them a few times in their dreams. A momentary encounter with their pure verse is heartbreaking; for a glimpse of their loveliness even death would be sweet. Gazing sadly, I wonder what will become of them; the passing clouds drift to the north, to the south (Leonardo).

The whole piece of the translation was good, and the sentence: for a glimpse of their loveliness even death would be sweet is very accurate and vivid. There is only one mistake, which was the word "heartbreaking”. “魂欲断” literally meant heartbreaking, but in the context of this poem, it depicted how those admirers loved the three sisters and even only a sight of their verse, those gentlemen could lose their mind.

\section{CONCLUSION}

$\mathrm{Yu}$ Xuanji is gaining increasing popularity in the west, and it is fairly to say that $\mathrm{Yu}$ is more appreciated in the west than in China, because she is not a female of virtue and discipline by Confucius moral standards. However, her poems which are vivid, highly personal, and full of emotion enormously resonate with the cult of individual expression in the west nowadays. What's more, her struggling and experimenting in different roles in her time has caught the attention of feminists (Leonard $\mathrm{Ng}$ on $\mathrm{Yu}$ Xuanji). It is really encouraging that more and more scholars with different culture background are devoting themselves in studying Chinese traditional poetry and even introducing the byways of poets which have been neglected for a long time. Their sincere work would be a great help in enabling Chinese culture more reachable. However, the obstacles encountered and mistakes made via the process also need our special attention, especially the translation problem. The examples I have shown in this paper, especially the lack of cultural knowledge, is just a tip of the iceberg in terms of translation issue. When researchers from the academia are conducting crosscultural researches, they should be more responsible, subtle, cautious and sincere, no matter in dealing with language interpretation and culture connotation. They should try every means to guarantee what they are going to present is faithful and meaningful.

\section{REFERENCES}

[1] David Young \& Jiann I. Lin. The Clouds Float North: The Complete Poems of Yu Xuanji, Bilingual Edition, Wesleyan University Press, 1998.

[2] Leonardo Ng: Leonardo Ng on Yu Xuanji, http://www.asymptotejournal.com/special-feature/leonard-ngon-yu-xuanji/

[3] The Complete Poems of Yu Xuanji, http://www.leonard-ng.com/complete-poems-of-yu-xuanji/

[4] Pease J. The Clouds Float North: The Complete Poems of Yu Xuanji. Translated by Young David and LinJiann I. Hanover, N.H. and London: University Press of New England, 1998. xviii, 75 pp. \$25.00.[J]. Journal of Asian Studies, 1999, 58(4):75-1130.

[5] 彭志宪,张炎, 唐代女诗人+鱼玄机诗编年译注. 新疆大学出版社. 
On Studying the Mis-Translation of the Poems of Yu Xuanji through the Comparison of Original Texts and Translation Version

AUTHORS' BIOGRAPHY

$\rightarrow$ Jinling, graduate student of Hunan University, China, Academic interests are English Literature and Language.

Citation: Jinling. "On Studying the Mis-Translation of the Poems of Yu Xuanji through the Comparison of Original Texts and Translation Version" International Journal on Studies in English Language and Literature (IJSELL), vol 6, no. 12, 2018, pp. 24-30. doi: http://dx.doi.org/10.20431/2347 -3134.0612003.

Copyright: () 2018 Authors. This is an open-access article distributed under the terms of the Creative Commons Attribution License, which permits unrestricted use, distribution, and reproduction in any medium, provided the original author and source are credited. 